\title{
Colonizar el espacio, habitar un lugar. Paisaje y ficciones de identidad en Fuegia (1991) de E. Belgrano Rawson*
}

\section{Carolina Grenoville}

\begin{abstract}
Docente de Semiología en el Ciclo Básico Común de la Universidad de Buenos Aires (Argentina) y becaria postdoctoral del Consejo Nacional de Investigaciones Científicas y Técnicas (Argentina). Correo electronico: cgrenoville@hotmail.com. La autora es Doctora y Licenciada de la Universidad de Buenos Aires (Argentina). Entre sus escritos recientes tenemos: "El surgimiento de la barbarie. Atavismo, venganza y fatalidad. El desperdicio de Matilde Sánchez", en Les Ateliers du Sal, No. 3 (2013) y "Memoria y narración. Los modos de re-construcción del pasado", en Adamios Revista de investigación social Vol 7, No. 13 (mayo-agosto 2010). Entre sus temas de interés estan los de Teoría Literaria, sobre todo aquellos referidos a la figuras del espacio público y la dimensión política de los interiores en la literatura política.
\end{abstract}

Recibido: 31 de marzo de 2014

Aprobado: 27 de abril de 2014

Modificado: 13 de mayo de 2014

Artículo de reflexión

DOI: http://dx.doi.org/10.15648/hc.27.2015.6

El presente artículo hace parte del proyecto: "Representaciones de la violencia. Perspectivas estéticas y políticas, planteos teóricos, nuevas manifestaciones y formas de expresión", financiado por la Universidad de Buenos Aires (Argentina).

Esta publicación está bajo una licencia Creative Commons Reconocimiento-NoComercial 4.0 
Colonizar el espacio, habitar un lugar. Paisaje y ficciones de identidad en Fuegia (1991) de E. Belgrano Rawson

\title{
Resumen
}

Fuegia de E. Belgrano Rawson recrea ficcionalmente el sometimiento y genocidio de los pueblos originarios de Tierra del Fuego por medio de estrategias y recursos propios de una poética positivista cuya actualización conduce paradójicamente a minar los presupuestos ontológicos sobre los que reposaba la literatura realista decimonónica. La novela socava, así, los parámetros formales de configuración del relato que incidieron en la constitución de una memoria social y de una identidad comunitaria en Argentina.

Palabras clave: Conquista, memoria, literatura argentina, realismo.

Colonizing space, inhabiting a place. Landscape and identity fictions in Fuegia (1991) by E. Belgrano Rawson

\begin{abstract}
Fuegia by E. Belgrano Rawson constitutes a fictional recreation of the subjugation and genocide of the indigenous peoples from Tierra del Fuego, by means of some positivist poetic's own resources and strategies, whose update leads paradoxically to undermine the ontological assumptions on which the nineteenth-century realistic literature rested. The novel thus subverts the formal parameters of the story's configuration that influenced the formation of a social memory and a community identity in Argentina.
\end{abstract}

Key words: Conquest, memory, Argentine literature, realism.

Colonizar o espaço, habitar um lugar. Paisagem e ficções de identidade em Fuegia (1991) de E. Belgrano Rawson

\section{Resumo}

Fuegia de E. Beltrano Rawson recria ficcionalmente a subjugação e genocídeo dos povos originários da Terra do Fogo por meio de estratégias e recursos próprios de uma poética positivista, cuja atualização conduz paradoxalmente a comprometer os orçamentos ontológicos sobre os que repousava a literatura realista decimonónica. A novela prejudicava, assim, os parámetros formais de configuração do relato que tiveram um impacto na constituição de uma memória social e de uma identidade comunitária na Argentina.

Palavras-chave: Conquista, memória, literatura argentina, realismo. 


\section{Coloniser l'espace, habiter un lieu. Paysage et fictions d'identité dans Fuegia (1991) de E. Belgrano Rawson}

\section{Résumé}

Fuegia, de E. Belgrano Rawson récrée au travers de la fiction, la soumission et le génocide des peuples originaires de la Terre du Feu, à l'aide de stratégies et de ressources propres d'une poétique positiviste dont l'actualisation amène, paradoxalement, à miner les présupposés ontologiques sur lesquels s'appuyait la littérature réaliste du XIX siècle. Ce roman creuse, ainsi, les paramètres formels de configuration du récit qui ont eu une incidence dans la conformation d'une mémoire sociale et d'une identité communautaire en Argentine.

Mots-clés: Conquête, mémoire, littérature argentine, réalisme.

\section{INTRODUCCIÓN}

Este artículo aborda la novela analizando la eficacia política simbólica de una arquitectura argumental que durante el siglo XIX en Argentina transformó el mundo efectivo de la acción para configurar una nueva cultura nacional poscolonial basado en las visiones seculares y expansionistas de la época. Por medio de la representación de las incursiones de viajeros europeos en territorio argentino con fines religiosos o comerciales -aunque como advierte Eduardo Belgrano Rawson, esas navegaciones eran una "mezcla de espionaje británico y de misión hidrográfica (nunca se sabía dónde terminaba el levantamiento de plantas y comenzaba el relevamiento político de las costas)"1- Fuegia ofrece un retrato peculiar de la consolidación de un régimen de veridicción ${ }^{2}$ y de relaciones de dominación que orientaron los proyectos políticos del nacionalismo decimonónico.

1 Eduardo Belgrano Rawson, "Sacarse de encima la historia", en La historia y la política en la ficción argentina, editado por Sergio Delgado (Santa Fe: Centro de Publicaciones de la Universidad Nacional del Litoral, 1995), 68.

2 Entiendo por "veridicción" los criterios según los cuales una comunidad establece la veracidad o falsedad de enunciados o formulaciones. Seguimos las formulaciones de Michel Foucault, Microfísica del poder (Madrid: Las Ediciones de la Piqueta, 1992) y Hermenéutica del sujeto (Buenos Aires: Fondo de Cultura Económica, 2001), 225 y ss.; y Algirdas J. Greimas, "The Veridiction Contract", New Literary History vol. 20.3 (1989): 651-660, teniendo en cuenta las observaciones al respecto de Paul Ricœur, Temps et récit. II. La configuration du temps dans le récit de fiction (Paris: Seuil, 1984), 84-85 y Donald Maddox, "Veridiction, Verifiction, Verifactions: Reflections on Methodology", New Literary History 20.3 (1989): 661-677. 
La novela de Belgrano Rawson se inscribe así dentro de una poética (y una política) de descolonización que muestra los alcances de distintas prácticas y estrategias de colonización las cuales, presuntamente inocentes o de manera explícita, se aplicaron en práctica en el Cono Sur dentro del proceso que Mary Louise Pratt denominó "anticonquista". Los viajes de exploración en territorio argentino que se narran en distintos textos ficcionales contemporáneos ${ }^{4}$ dejan entrever otros fines, diferentes de los que se enuncian abiertamente y dan cuenta de los modos como las empresas artísticas, científicas, religiosas o comerciales contribuyeron a afirmar la hegemonía y la superioridad europeas. Las representaciones de las travesías de estos aventureros ponen de relieve (a la vez que desarticulan) una singular comprensión del espacio que presupuso relaciones funcionales concretas entre los sujetos y con el territorio, según una lógica pragmática y economicista que se consolidaría posteriormente con los programas político-culturales de las élites nacionales.

Los textos "clásicos" de la literatura argentina -como La cautiva (1837) y El matadero (1871) de Esteban Echeverría, Facundo (1845) de Domingo F. Sarmiento y Amalia (1851-1855) de José Mármol, por mencionar algunos- mediante los cuales se libraría la batalla cultural de emancipación del pensamiento y "conquista del genio americano" surgieron, paradójicamente, como han demostrado Mary Louise Pratt, Adolfo Prieto y Ricardo Cicerchia, entre otros ${ }^{6}$, de la asimilación de tópicos, figuras, premisas y perspectivas propios de los diarios de una serie de viajeros europeos (en

3 Mary Louise Pratt, Ojos imperiales. Literatura de viajes y transculturación (Buenos Aires: Fondo de Cultura Económica, 2011, primera edición 1992), 35, 65 y 84, emplea el término "anticonquista" para designar "una visión utópica e inocente de la autoridad europea global" desde la cual se naturalizó "la presencia y la autoridad globales de la Europa burguesa" en contraposición con las articulaciones abiertamente imperiales de la Conquista española.

4 Ver, por ejemplo, Libertad Demitrópulos, Un piano en bahía desolación (Madrid: EDAF, 2001, primera edición 1994); Juan José Saer, Las nubes (Buenos Aires: Seix Barral, 1997); Sylvia Iparraguirre, La tierra del fuego (Buenos Aires: Alfaguara, 1998); César Aira, Un episodio en la vida del pintor viajero (Rosario: Beatriz Viterbo Editora, 2000).

5 Juan Bautista Alberdi, "Fragmento preliminar al estudio del derecho", en Escritos de Juan Bautista Alberdi: el redactor de la Ley, editado por Oscar Terán (Bernal: Universidad Nacional de Quilmes, 1996), 67.

1806 Mary Louise Pratt, Ojos imperiales; Adolfo Prieto, Los viajeros ingleses y la emergencia de la literatura argentina (1820-1850) (Buenos Aires: Fondo de Cultura Económica, 2003, primera edición 1996); Ricardo Cicerchia, Journey, Rediscovery and Narrative: British Travel Accounts of Argentina (London: Institute of Latin American Studies, 1998). 
su mayoría ingleses). Ellos recorrieron América del Sur en busca de potenciales mercados de consumo y centros de inversión y de explotación. La literatura fundacional se entrelaza, desde esta perspectiva, a partir de una misma sensibilidad legal que compone caracterizaciones vernáculas de lo que sucede e imaginarios vernáculos de lo que puede suceder, esto es, "relatos sobre los hechos proyectados en metáforas sobre los principios"?

En este sentido, Fuegia constituye una verdadera relectura del itinerario completo que traza esa red de textos: desde los sentidos utilitarios que orientaron los viajes y la escritura en el siglo XIX, también pasa por la representación simbólica del espacio y de los otros a partir de la perspectiva, en palabras de Jens Andermann, del "hombre observador" - "punto de vista arquetípico del discurso colonizador que contempla un mundo objetivizado como paso previo a la toma de posesión" -; hasta las matanzas, secuestros y usos abyectos de los cuerpos que también tuvieron lugar dentro de este movimiento de expansión imperial, aunque poco se haya escrito al respecto en la época. En el texto analizado, los distintos viajes y emprendimientos religiosos y comerciales son narrados simultáneamente con el genocidio de los fueguinos por medio de una focalización móvil que contempla desde la creación de cuadros y el establecimiento de un campo y su fuera-campo a la asunción de la perspectiva de alguno de los personajes. Los desplazamientos y acercamientos de la mirada del narrador permiten situar el punto de vista en un cuerpo concreto ubicado en un mismo plano al del objeto retratado, crea, de este modo, representaciones fragmentarias del espacio y de los otros.

Los comienzos históricos, literarios y semióticos de la nacionalidad componen necesariamente una geografía inestable. En ese terreno anegado, la novela vacila entre la determinación y la indeterminación, la identidad y la dispersión, la quietud y el movimiento, la verosimilitud y la inverosimilitud, en busca de "lo que se encuentra al comienzo histórico de las cosas",

7 Clifford Geertz, Conocimiento local. Ensayos sobre la interpretación de las culturas (Barcelona: Paidós, 1994), 242.

8 Jens Andermann, "Crónica de un genocidio: últimas instantáneas de la frontera", en Historia crítica de la literatura argentina. II. La lucha de los lenguajes, editado por Julio Schvartzman (Buenos Aires: Emecé, 2003), 360. 
que no es, como sostiene Michel Foucault, "la identidad aún preservada de su origen -es la discordia con las otras cosas, es el disparate" ${ }^{\text {. Existe, }}$ en efecto, en esta narración una tensión entre la forma simbólica y los discursos socialmente codificados que adopta, y los caminos que luego abre a contrapelo de las expectativas generadas en el lector. El punto de partida será precisamente sendas ya transitadas. Así lo indican al menos la recurrencia del motivo del viaje y de determinados procedimientos formales, como la composición del "escenario" donde se ubica la misión del reverendo Dobson por medio de una visión panorámica y la inclusión de fotografías al comienzo de cada capítulo con las cuales se identifican a los distintos personajes de la novela.

El relato de la conquista y colonización del territorio se lleva a cabo, entonces, a partir de estrategias y operaciones análogas a las empleadas en esos textos previos. Una hojeada rápida a la novela permite identificar distintos recursos prototípicos de los géneros en los cuales esa imaginación imperial cobró forma y se naturalizó, como las fotografías en la portada y al comienzo de cada capítulo del texto de Belgrano Rawson que relacionan a este relato ficcional con el discurso etnográfico y el álbum familiar en los cuales el retrato asume un valor o bien científico o bien pintoresco. Ahora bien, en Fuegia se urde asimismo un régimen de veridicción distinto del que rige estos géneros realistas socavando los presupuestos ontológicos sobre los cuales reposaban estas distintas escrituras del yo. La representación fragmentaria del derrotero de Camilena y Tatesh por medio de una focalización enunciadora se propone restituir una experiencia individual, a hacer de los sucesos, inefables por definición, algo asequible y transparente sin necesidad de subsumirlos a un lenguaje público, a una finalidad o una dirección a un sentido apropiado o, si se quiere, a la propiedad de un sentido. El paisaje y el retrato se constituyen paradójicamente en el suelo propicio desde donde minar al sujeto en que se encarnaba la visión metropolitana, centro de las concepciones estéticas del siglo XIX, y fundamento último de la veracidad de lo narrado y del valor científico que se le confería a la exploración en tierras "exóticas"

9 Michel Foucault, Microfísica del poder, 10.

10 En efecto, como advierte Ricardo Cicerchia, Journey, Rediscovery and Narrative, 4, los relatos de viaje se organizaron con base en dos lenguajes opuestos y complementarios: el científico y el experiencial. 


\section{El ESPACIO DE LA MEMORIA: LA DESTERRITORIALIZACIÓN DE LA HISTORIA}

Fuegia de Eduardo Belgrano Rawson constituye una recreación ficcional de una serie de referentes históricos por medio de la puesta en funcionamiento de una poética positivista: la novela narra el sometimiento y genocidio de los pueblos originarios que habitaban Tierra del Fuego. A la par, pasa revista a distintas formas simbólicas mediante las cuales la ciencia y el arte legitimaron, a la vez que capitalizaron, la acción imperial de los países europeos, como la fotografía, los zoológicos humanos, los trofeos de caza, pero también procedimientos formales singulares de la literatura realista y del paisajismo. El punto de partida de esta novela fue, como declara su autor en "Sacarse de encima la historia", "una historia": "Cuando yo decidí escribir sobre los indios fueguinos fue por una historia. Siempre hay una historia, una historia que marca. Yo me encontré con la historia de Jimmy [sic] Button, John Mister, Boat Memory y Fuegia Vázquez [sic] de manera accidental como siempre pasan estas cosas"11.

Un testimonio de la historia de estos fueguinos se encuentra en Journal of Researches into the Natural History and Geology of the Countries Visited during the Vyage of H.M.S. "Beagle" round the World, under the Command of Capt. Fitz Roy, R.N. de Charles Darwin, publicado por primera vez en 1839, después de cuatro años de travesía ${ }^{12}$. En ese viaje comandado por Fitz Roy, Darwin conoció a tres de los cuatro yaganes (uno había muerto al poco tiempo de llegar a Inglaterra) que Fitz Roy se disponía a restituir a su lugar de origen luego de haberlos tomado por la fuerza en un viaje anterior al extremo meridional del país entre 1829 y 1830 y trasladado a Europa con la intención de que recibieran educación y aprendieran la religión.

Recién cuando se aproximan a las costas de Tierra del Fuego y establecen los primeros contactos con los habitantes del lugar, el joven naturalista repara en los tres fueguinos que viajaban con ellos. El contraste entre unos y otros no puede ser mayor tal y como se constata en su diario: "It seems yet

11 Eduardo Belgrano Rawson, "Sacarse de encima la historia", 68.

12 Un análisis de las relaciones intertextuales entre Fuegia y el diario de Darwin puede encontrarse en:

Florencia Garramuño, Genealogías culturales. Argentina, Brasil y Uruguay en la novela contemporánea (1981-1991) (Rosario: Beatriz Viterbo Editora, 1997). 
wonderful to me, when I think over all his [Jemmy Button's] many good qualities, that be should have been of the same race, and doubtless partaken of the same character, with the miserable, degraded savages whom we first met here" ${ }^{\text {"13 }}$. A diferencia del profundo rechazo que le inspira, una vez en tierra firme, el espectáculo que ofrece el grupo de fueguinos con sus rostros pintados y cubiertos tan solo con una manta de piel de guanaco sobre los hombros, se maravillará ante el comportamiento de estos que se hallan a bordo, en especial, el de Jemmy Button, quien, como declara el propio Darwin, era el favorito de la tripulación. La alegría, la amabilidad y la discreción de Button pero sobre todo su prolijidad y pulcritud extremas (siempre llevaba guantes, usaba el pelo corto, se amargaba si se le ensuciaban los zapatos, siempre muy bien lustrados, se miraba con regularidad al espejo, entre otras cosas ${ }^{14}$ ) parecían constituir una demostración cabal de que ya no había en él vestigio alguno de los usos y costumbres locales, sobre todo si se contrastaban sus maneras con las actitudes de sus congéneres, que Darwin encuentra "abyectas", y que lo llevan a concluir que las diferencias que existen entre esos "salvajes" y un "hombre civilizado" eran aún mayores que las que puede haber entre un animal salvaje y uno doméstico ${ }^{15}$.

Sin embargo, como después corroboraría el propio Fitz Roy, su "pigmaliónico experimento" no resultó tan exitoso como pareció en un primer momento $^{16}$. Al poco tiempo de hallarse nuevamente entre los suyos este muchacho que supo ser un caballero inglés ya andaba nuevamente desnudo y embadurnado con grasa de lobo:

"Era Jimmy Button, quien a pesar de haber vivido más de tres años entre hombres civilizados, había retornado a su estado natural.

13 Charles Darwin, Journal of Researches into the Natural History and Geology of the Countries Visited during the Voyage of H.M.S. "Beagle" round the World, under the Command of Capt. Fitz Roy, R.N, con base en la edición aumentada y corregida de 1845 (London - New York - Melbourne: Ward, Lock and Co., 1890), 150. http://nzetc.victoria.ac.nz/tm/scholarly/DarJour-fig-DarJoTit.html (7 de enero de 2014).

14 Charles Darwin, Journal of Researches, 150.

15 Charles Darwin, Journal of Researches, 148.

18416 El mito clásico de Pigmalión se actualizó y realizó durante el siglo XIX antes en los márgenes del Imperio Británico como experimento etnográfico rayano con la zoología que como reelaboración literaria en el marco del esteticismo en The portrait of Dorian Gray (1890) de Oscar Wilde y luego con la obra Pygmalion (1913) de Bernard Shaw. 
No obstante su repugnante apariencia le hicieron subir a bordo, y una vez que se hubo lavado, y vestido como marinero, fue llevado a almorzar con Fitz Roy y sus oficiales"17.

Ahora bien, de este episodio -que contiene prácticamente todos los ingredientes de lo novelesco- la novela solo conservará algunos pocos elementos: el título del texto, que se corresponde con el nombre de la joven muchacha a la que Fitz Roy tomó como cautiva; un epígrafe en "memoria de Fuegia Basket, Jemmy Button, York Minster y Boat Memory, quienes fueron una vez a Inglaterra". Finalmente, algunos datos puntuales que tanto Darwin como distintos misioneros anglicanos y salesianos consignaron en sus diarios y que reaparecen en este relato ficcional (las conocidas cacerías sobre todo de selknam organizadas a instancias de las grandes compañías ovejeras en las cuales se les cortaban las orejas para luego reclamar el pago de una libra esterlina por cada fueguino muerto si es uno de ellos ${ }^{18}$ ). Como afirma el propio Belgrano Rawson en esa misma charla: "Tenía tema, principio, remate. Todo. Y ese era el problema. Y de tal calibre que a medida que trabajaba advertí que nunca iba a poder escribir esta historia. Porque era historia. Y que si yo iba a escribir alguna novela sobre los fueguinos me tenía que olvidar prolijamente de la historia y escribir otra cosa. Y ahí empiezan los problemas para un escritor" ${ }^{19}$.

En efecto, la dedicatoria de la novela ya constituye un modo de "sacarse de encima la historia" en tanto que sitúa al lector en un plano distinto, el del horizonte del recuerdo, y promete, desde el umbral del texto, la evocación de un hecho traumático: la historia desechada reingresa ahora bajo la forma de una memoria. Asimismo, esos restos -los nombres propios, la alusión al viaje a Inglaterra que efectivamente ocurrió- se mezclan desde un principio con las fotografías tanto de fueguinos como de europeos que aparecen en la portada y al comienzo de cada capítulo imprimiéndole a este relato narrado en tercera persona la forma de las escrituras del yo.

17 Lucas E. Bridges, El último confín de la Tierra (Buenos Aires: Emecé, 1952), 25.

18 "¿Sabe lo que pasó el otro día? A una parriken preñada le abrieron la panza de un machetazo. ¿Comprende?/ -No./ -Cuatro orejas, en lugar de dos./ -Vamos, padre. No se tragará todo eso...”. Eduardo Belgrano Rawson, Fuegia, 175.

19 Eduardo Belgrano Rawson, "Sacarse de encima la historia", 70. 
Este desplazamiento desde la "Historia" a la historia personal se asocia con un cuestionamiento al discurso historiográfico y etnográfico en particular y al discurso realista en general, lo cual se traduce en la singular relación que la novela establece con sus fuentes. En palabras de Luciana Mellado: "Fuegia se instala explícita e insistentemente en el terreno de la metaficción. Por un lado, recuerda la historia del genocidio sufrido por los indígenas fueguinos en el siglo XIX y la modificación radical de sus espacios propios, y, por otro lado, renuncia a reproducir la versión historiográfica de estos hechos" ${ }^{20}$.

La tensión entre la recuperación de ciertos procedimientos de la novela realista y su deliberado trastrocamiento lleva aquí a una organización singular de la materia narrativa que se caracteriza por el desvanecimiento de las referencias concretas -espaciales, temporales, étnicas, nacionales, etc.-. Esto es, los "datos" históricos, para colocar en un primer plano la elusiva realidad de una experiencia. En este sentido, si bien el tópico del viaje es central en el texto, Fuegia no asume la forma de un diario de viaje (género hipercodificado en el cual se afianzó la mirada imperial) sino que constituye una novela sobre viajes en la cual se articulan los desplazamientos de los colonos con los de los habitantes de la región componiendo así una zona de contacto eminentemente compleja, cambiante e inestable, que cristaliza en los títulos de los capítulos (varios remiten a lugares y pertenecen al español y al inglés). De igual modo, se desestima aquí tanto la autoridad de una primera persona que atestigüe en favor de la veracidad de lo narrado como la perspectiva omnisciente del realismo literario y de las vistas del paisajismo en función de la cual se componía un paradójico punto de vista trascendental con llamativos rasgos nacionales o locales. Se opta, en cambio, por un narrador en tercera persona que se mueve entre los puntos de vista de los distintos personajes para restituir desde allí la vivencia de quienes no han podido testimoniar.

El testimonio imposible solo puede encontrar un lugar en la Historia a través de la intermediación de la literatura la cual, antes que de los hechos se ocupa del "espíritu" de lo que aconteció: la pregunta que definìo la

20 Luciana Mellado, La Patagonia y su literatura: unidad y diversidad multiforme (Comodoro Rivadavia: Universidad Nacional de la Patagonia San Juan Bosco, 2010), 24. 
escritura de la novela no ha sido qué pasó (que hubiese llevado a restituir lugares, cifras, fechas, identidades -étnicas, nacionales-, y que presupone, asimismo, la reconstrucción imposible de una totalidad que solo conocemos parcial y fragmentariamente a partir de los registros escritos y fotográficos de los colonizadores) sino, en palabras nuevamente de Belgrano Rawson, cómo ha sido: “¿Cómo habla un fueguino? ¿Cómo hace el amor? ¿De qué habla con la mujer por las noches?"21. Pero, además, la ficción al desentenderse de la exigencia de veracidad que rige otros discursos puede fantasear con reparaciones o pequeños actos de justicia poética allí donde el Estado en el mejor de los casos ha brillado por su ausencia: la venganza de Lucca, el único sobreviviente de los hijos de Camilena y Tatesh (y de la cruenta masacre de Lackawana que se narra en el capítulo X en el cual mueren, según los cómputos de uno de sus perpetradores, doscientos fueguinos) sería uno de esos actos.

Por último, y en concordancia con el resto de las elecciones formales, el desarrollo de la narración asume una forma fragmentaria y desordenada en las cuales los distintos hilos de la trama argumental componen, como señala Florencia Garramuño, un verdadero "rompecabezas" en el cual "siempre faltan piezas"22. La alteración en la ordenación lógico-cronológica del conjunto referencial de la obra, el hecho de que algunos personajes aparezcan identificados bajo distintos nombres (el nombre indígena o el cristiano), o que un mismo hecho se cuente desde distintas perspectivas, dificultan la reconstrucción de la historia de la familia de fueguinos que protagoniza la novela. Luego de que unos cazadores la violan, Camilena, junto a Tatesh, su compañero, y sus tres hijos, Jaro, Isabela y Lucca, abandonan la misión donde aún vive la viuda del reverendo Dobson ubicada en la costa y parten hacia el norte decididos a instalarse en los dominios de los parrikens (etnia a la que pertenece Tatesh), en ese entonces en disputa con codiciosos y sanguinarios criadores de ovejas. En ese viaje por un territorio completamente alambrado y custodiado por mastines traídos especialmente de Europa para la cacería de fueguinos, los niños son brutalmente asesinados por los perros de Larch, un empleado de "The Fuegia Land Farming Co.”, a excepción del pequeño Lucca, quien queda en po-

21 Eduardo Belgrano Rawson, "Sacarse de encima la historia", 70.

22 Florencia Garramuño, Genealogías culturales, 41. 
der de Larch como esclavo. Si bien no se explicita cuál fue el desenlace de los padres, se sobreentiende que corrieron una suerte similar a la de sus hijos. Asimismo, las distintas unidades que integran las secuencias de esta trama señalan metonímicamente y de manera ostensible la colonización y la transformación política, económica y cultural de la Patagonia por esos años: la historia que Fuegia individualiza se constituye así en la historia de los distintos pueblos que habitaban el archipiélago.

La novela dramatiza, de este modo, en un nivel formal la imposibilidad de reconstruir una historia total, las lagunas en donde se interrumpen las confusas e incluso contradictorias versiones sobre lo acontecido:
"Bueno: la isla se llenó de fantasmas. Cada tanto, algún forastero preguntaba por ellos. Periodistas, profesores de historia, gente por el estilo. Querían averiguar la suerte de Camilena Kippa y de Tatesh Wulaspaia, mientras tomaban toda clase de notas acerca de los misioneros de Abingdon o de Beltrán Monasterio. Pero su principal objetivo era la matanza de Lackawana. Muchos los escuchaban incrédulamente, convencidos de que a las víctimas se las había llevado la gripe o sus propias desavenencias"23.

Estos "blancos", que son inherentes a toda reconstrucción histórica, se expanden cuando los hechos referidos se enmarcan dentro de un conjunto de operaciones más amplio que contempla desde la subversión, el enmascaramiento y la falsificación de la realidad hasta el borramiento deliberado de las "huellas". En este sentido, José Maristany, en su análisis de la novela de Belgrano Rawson, advierte puntos de contacto entre la representación de la historia de este grupo de fueguinos y la experiencia de la última dictadura militar: "es preciso destacar el aspecto más importante en esta cadena de repeticiones, se trata de la categoría de desaparecidos. Los indígenas de Tierra del Fuego “desaparecieron”, se convirtieron en fantasmas, adoptaron esa extraña e inverosímil identidad reservada a los objetos de exterminio" 24 .

23 Eduardo Belgrano Rawson, Fuegia, 29.

24 José Maristany, "Un arte de la memoria: Fuegia de Eduardo Belgrano Rawson", Argos Vol. 42-43 (2005): 88. 
Fuegia en cierto modo intenta contrarrestar esa obliteración: la singular combinación de distintos procedimientos de representación en la configuración de subjetividades y espacios posibilita la restitución de una memoria perdida. Bajo cada una de las fotografías que aparecen en la novela figura una leyenda con la cual se identifican a los sujetos retratados con alguno de los personajes ficcionales que integran esta historia. La particularidad de la fotografía radica, precisamente, en que la imagen representada se inscribe como huella de lo real: "La técnica fotográfica inaugura un nuevo modo de representar y ver el mundo cuyo fundamento es el mismo desarrollo científico; un nuevo modo en el cual, por primera vez, la representación ya no es un signo arbitrario del objeto, sino una porción de realidad robada al mundo" 25 .

La inclusión de una fotografía de archivo en un relato ficcional o, en otras palabras, los usos del "documento" para ilustrar la ficción contribuye en principio a proporcionar una mayor verosimilitud al discurso ficcional, a reforzar una tendencia al realismo de la novela. Ahora bien, este vínculo lleva paradójicamente a cuestionar, en un segundo momento, la "realidad" representada en el retrato y detona una serie de interrogantes: ¿quién falsea, en definitiva, la imagen: la novela que atribuye una falsa identidad a un rostro sin nombre o el etnógrafo positivista de fines del siglo XIX que metonímicamente identifica el rostro con un grupo, una etnia?; ¿quién distorsiona la historia?; ¿qué es la historia, en suma, sino una distorsión?

Hay en la novela un trastrocamiento de los usos convencionales de las fotografías de los fueguinos. Si en el documento etnográfico las fotografías están destinadas a significar una raza, en Fuegia, por el contrario, estas mismas imágenes enmarcadas en el relato novelesco convocan una subjetividad. Esta operación consiste en un desplazamiento del punto de vista y un acercamiento al objeto representado. La ficción se vuelve afección al mirar al Otro tal y como nos miramos a nosotros mismos a través de la fotografía. Los retratos fotográficos no se presentan en Fuegia como figuraciones de los fueguinos para reconocerlos, sino como retratos de un álbum familiar que llevan a mirar con los mismos ojos a europeos y nativos para recordarlos.

25 Paola Cortés Rocca, "Cuerpos y promesas. El retrato fotográfico en el siglo XIX”, Filología, Vol. XXXI No. 1-2 (1998): 44. 
La novela construye, de este modo, un punto de vista que deconstruye la mirada distanciada que se presume universal y transhistórica de los discursos cientificistas.

En rigor, el realismo literario, sin necesidad de recurrir a este artefacto técnico, hacía como si el signo pudiese efectivamente representar el referente sin la intermediación del significado, como advierte Roland Barthes a propósito de la secuencia descriptiva, que aproxima el discurso literario a una representación icónica y tiene como finalidad autentificar lo real ${ }^{26}$. Coherente con el desplazamiento del punto de vista que vimos más arriba en relación con las fotografías, la novela desestima la descripción para caracterizar a los distintos personajes y prioriza, en cambio, el relato de las acciones que estos realizan, los sentimientos que experimentan -la ternura, la furia, el miedo, etc.-, su discurso, su modo de andar. Asimismo, como observa Maristany, la ficcionalización de las etnias a las que pertenecen los mismos forma parte de este mismo movimiento ${ }^{27}$. A partir de las características de los distintos personajes, es posible identificar a Camilena y los suyos con los yaganes y a Tatesh con los selknam, aunque en la novela el narrador se refiera a estos bajo los términos ficcionales de "canoeros" o "canaleses" y parrikens. De este modo, si por un lado la organización de la población en etnias en función del espacio en que habita, la fisonomía y las prácticas que realiza pareciera inscribir al texto dentro de un paradigma realista, por el otro, el empleo de una denominación inexistente para referirse a estos grupos pone en entredicho la identificación con la realidad.

Por último, y en sintonía con los usos que hace la novela de la fotografía y la práctica de la nominación, se destaca la modalidad con la cual el texto se apropia de los "datos" provenientes del discurso científico e historiográfico, como el penoso destino que los yaganes tenían reservado a las mujeres mayores que ya no podían salir a pescar. Las variaciones en el tratamiento que de este mismo hecho hace el diario de Darwin y la novela de Belgrano Rawson ponen de relieve dos tendencias contrapuestas en la representación de la alteridad: la primera ofrece una descripción distanciada de los

26 Roland Barthes, "El efecto de realidad", en El susurro del lenguaje. Más allá de la palabra y la escritura (Barcelona: Paidós, 1994), 179-187.

27 José Maristany, "Un arte de la memoria”, 80. 
otros destinada a rechazar la común pertenencia de europeos e indígenas a una misma humanidad; la segunda, en cambio, contempla las distintas causas y contingencias que inciden en una historia excepcional, colocando al lector ante las mismas encrucijadas que deben afrontar los personajes.

"Camilena acababa de cumplir nueve años. Por aquellos días babia visto ahogar con humo a una vieja, durante unos temporales funestos en que las tormentas echaron del mar a su pueblo durante semanas enteras. Cuando las cosas se pusieron muy negras, algunos desesperados empezaron a desquitarse con la gente que nunca salía de pesca. "A mí no van a agarrarme", dijo su madre esa noche, mientras planeaban la fuga. Eso habia sido antes de Abingdon y de conocer a Tatesh, cuando todavía vivian en el País de las Lluvias Perpetuas" 28 .

En su diario, por el contrario, Darwin apuntaba:

"The different tribes when at war are cannibals. From the concurrent, but quite independent evidence of the boy taken by Mr. Low, and of Jemmy Button, it is certainly true, that when pressed in winter by hunger they kill and devour their old women before they kill their dogs: the boy, being asked by Mr. Low why they did this, answered, "Doggies catch otters, old women no". This boy described the manner in which they are killed by being held over smoke and thus choked; he imitated their screams as a joke, and described the parts of their bodies which are considered best to eat. Horrid as such a death by the hands of their friends and relatives must be, the fears of the old women, when hunger begins to press, are more painful to think of; we were told that they then often run away into the mountains, but that they are pursued by the men and brought back to the slaughter-house at their own firesides!" 29.

En Journal of Researches... el empleo de verbos en presente y la apelación a la figura de un informante pretendidamente fiable e imparcial contribuyen

28 Eduardo Belgrano Rawson, Fuegia, 61. Las bastardillas son mías.

29 Charles Darwin, Journal of Researches, 155. Las bastardillas son mías. 
a presentar el asesinato de estas mujeres como un hábito que se practica regularmente entre los fueguinos, otra manifestación más de su "salvajismo”. En la novela de Belgrano Rawson, por el contrario, los tiempos verbales propios de la narración (el pretérito perfecto y el pluscuamperfecto) y los adjetivos que se emplean ("funestos", "desesperados") dan cuenta de que se trata de un suceso singular. La mirada etnográfica de Darwin construye a partir del relato de dos testigos un hábito y normaliza un comportamiento, niega asi a los fueguinos -su objeto de estudio- una trayectoria de opciones y alternativas, una historia. Fuegia construye con "fragmentos de realidad" una ficción en la cual la representación fotográfica, la observación etnográfica y la clasificación científica se refuncionalizan con el objeto de dramatizar la inadecuación radical entre el discurso y el referente.

Podemos afirmar entonces, que frente al prestigio del sucedió que regía los distintos géneros realistas decimonónicos, como la novela, el diario, la literatura documental, la fotografía, entre otros, y que daba cuenta de un gusto por el efecto de realidad que suscitaban principalmente las referencias con un claro valor indicial ${ }^{30}$, el prestigio que rige ahora la práctica artística en general y la literaria en particular es, por el contrario, el del no sucedió. La literatura asume, de este modo, un deber de irrealidad que exige la restitución del mito al plano imaginario o, mejor dicho, la presentación de lo que se creía real como el mundo posible de un discurso de poder. Serán esos mismos géneros muchas veces, bajo otra estructura, los que instarán a una revisión de lo acontecido, revisión que, como no apunta a los contenidos, sino, como vimos, a la forma del significado, no halla ningún límite exterior al discurso. La ilusión de un referente extratextual que regula la expresión se ha desvanecido: en palabras de Barthes, "hoy en día, se trata de lo contrario, de vaciar el signo y de hacer retroceder infinitamente su objeto hasta cuestionar, de una manera radical, la estética secular de la 'representación"' 31.

En relación con el espacio advertimos una operación análoga. La novela se abre con la configuración del "escenario" a partir de una mirada desde las alturas. La focalización en el punto de vista de los guanacos parece pa-

$30 \quad \mathrm{Al}$ respecto, véase Roland Barthes, "El efecto de realidad", 175-176.

$31 \mathrm{Al}$ respecto, véase Roland Barthes, "El efecto de realidad", 187. 
rodiar esa perspectiva "a vuelo de pájaro" desde la cual divisar un paisaje virgen a la que eran tan adeptos los románticos:

\begin{abstract}
"En invierno bajaban al mar. Llegaban hambrientos de la montaña y antes de trasponer los últimos árboles contemplaban por largo rato, con sus ojos resplandecientes, la oscuridad de la costa. La playa estaba invariablemente vacía, pero los guanacos tenían buena memoria y no daban un paso en la arena hasta que el sol salía del todo y disipaba la niebla"32.
\end{abstract}

Allí, en ese escenario "salvaje" se ubica el único lugar estable que se representa en la novela: Abingdon, la misión del reverendo Dobson, donde viven Camilena y su familia hasta que emprenden el viaje final. Este enclave de la civilización se construye a partir del punto de vista arquetípico del discurso colonizador -la observación distanciada y el régimen de la semejanza- que anticipa la apropiación violenta de esa región que se narrará a continuación. En el boceto de la misión que el matrimonio prepara en su juventud desde Inglaterra ${ }^{33}$ y en las vistas en perspectiva de ese sitio $^{34}$, el espacio informe y heterogéneo se presenta como susceptible de ser modelado en función de una concepción de lugar y de un esquema de relaciones sociales preexistente.

32 Eduardo Belgrano Rawson, Fuegia, 15.

33 "Había jurado que aquellos saludos hipócritas jamás llegarían a perjudicar su tesoro: la memoria de los días en que merendaban con Dobson en Saint James Park y dibujaban la misión prometida sobre el papel de los bollos" (Eduardo Belgrano Rawson, Fuegia, 18); "Charlaron del futuro viaje a Sudamérica. Dobson dibujó la misión sobre el papel de los bollos. Había un grupo de canaleses entonando sus himnos y un paquebote en el horizonte. Los canaleses figuraban como 'naturales amistosos' en todas las publicaciones del almirantazgo, de modo que agregó un nativo haciendo cabriolas. Su mujer le suplicó que dibujara una huerta. Dobson puso la huerta y metió algunas ovejas. Estuvo tentado de añadir un cementerio, pero desistió a último momento. Ella estudió bien el dibujo y concluyó que nada faltaba. Trató vanamente de hallarle algún parecido con su aldea de Sussex" (Eduardo Belgrano Rawson, Fuegia, 66. Las bastardillas son mías).

34 "Un fuego encendido desde siempre, varias vacas encerradas, una verja pintada de rojo, los canteros de malvones y un perfume a café que llegaba hasta el muelle. Visto desde cubierta, podía confundirse con un paisaje irlandés y era una tentación para cualquiera" (Eduardo Belgrano Rawson, Fuegia, 17); "Una tarde su marido venía remando en dirección a la playa. Ella lo esperaba en el muelle, mientras el sol la besaba. Había ovejas paciendo en la orilla y las cotorras reventaban el bosque. El viento estaba cayendo. Para que el cuadro fuera perfecto, faltaba el arzobispo en el bote al lado de su marido" (Eduardo Belgrano Rawson, Fuegia, 239. Las bastardillas son mías). 
Pero Fuegia da cuenta además de toda una serie de estrategias de individuación, normalización y sujeción de los cuerpos con lo cual se procuró "adecuar" el espacio meridional al plano. La llegada de los europeos a Tierra del Fuego trastoca por completo el modo de vida de los habitantes del lugar. Dentro de la misión, los fueguinos deberán adaptarse a los usos y costumbres del mundo civilizado, desde la adopción de un nombre cristiano y una nueva religión hasta la sustitución del quillango por vestimenta europea. Fuera de ella, se verán igualmente privados de circular libremente por la región y confinados a aquellas zonas que el blanco generosamente le concede. Significativamente, con la muerte del reverendo, Abingdon acaba por adquirir el cariz de un paisaje fantasmagórico. La viuda vive sumida en sus recuerdos, ya prácticamente no quedan canaleses en la misión y ningún barco escoge ese sitio para hacer una parada. La presencia espectral de la viuda, que perdura como un único rastro del sueño de colonización, emparenta este enclave colonial con un museo, sitio por antonomasia donde exhibir la naturaleza muerta.

Abingdon se constituye de este modo en la contraimagen del pabellón de Sudamérica en la Exposición Universal de París que monta Bongard, un promotor de espectáculos, al quien se le ocurrió la brillante idea de exhibir a los parrikens y hacerlos actuar su identidad frente a los europeos. La reconstrucción arbitraria y casi carnavalesca del "hábitat" y el estilo de vida del grupo de aborígenes americanos de acuerdo con las expectativas del público europeo es en alguna medida equiparable a la reconstrucción a escala reducida de la civilización en el extremo sur de América. Solo que allí como acá serán los blancos quienes les impongan a los fueguinos un papel que actuar y una función que cumplir dentro de una sociedad que imaginan y proyectan a su antojo. Cuando la muestra parisina ya está por concluir, su autor logra finalmente que los indios hagan lo que él pretende: "El espectáculo fue mejorando, hasta que un día Bongard consiguió que los propios caníbales atendieran las mesas con sus ponchos bolivianos" 35 .

Ahora bien, las vistas panorámicas, los planos y las referencias toponímicas con que se titulan muchos capítulos que intervienen en la composición

35 Eduardo Belgrano Rawson, Fuegia, 25. 
de la espacialidad donde se desarrollan los hechos se complementan en la novela con lo que De Certeau denomina una "enunciación peatonal", esto es, la focalización en los modos como los personajes actualizan el conjunto de prohibiciones y posibilidades que organiza un orden espacial: "la enunciación peatonal presenta tres características que de entrada la distinguen del sistema espacial: lo presente, lo discontinuo, lo 'fático'36. La novela renuncia, entonces, a la descripción distanciada del paisaje (descripción que coincide con la constitución de un orden -en el plano de Abingdon que dibujan el reverendo Dobson y su mujer antes de viajar a estas tierras ya figuran la huerta y un grupo de canaleses entonando sus himnos $^{37}-$ ), para cederle el lugar a otro modo de espacialización a partir de la inscripción de los cuerpos en movimiento en el texto: el recorrido. En este punto, Fuegia restituye una estructura predictiva (estructura que, como vimos anteriormente, faltaba en el retrato de los fueguinos que lleva a cabo Darwin) en función de la cual se organiza la narración de los distintos hechos de violencia (la violación de Camilena a manos de los loberos, la consecuente venganza de Tatesh, su compañero, y, finalmente, la matanza de Lackawana) tendientes a un mismo fin: el borramiento de los fueguinos del mapa ${ }^{38}$.

\section{CONCLUSIÓN}

El acercamiento del punto de vista y la construcción de un espacio empírico a partir de la narración de acciones acaban por configurar una suerte de des-identidad que no solo connota el destino trágico de estos sujetos sino también la imposibilidad de recuperar el pasado. La descripción totalizadora, clara y distinta de esa pequeña porción de "mundo civilizado" en el hemisferio austral del continente en donde a cada cual le corresponde un papel propio se contrapone con el relato fragmentario, acelerado y confuso del avance de esta familia de fueguinos hacia la muerte. Pero el cambio en la focalización también trae aparejada una suerte de "presentización” de la Historia, la actualización de un tiempo histórico. El pasado

36 Michel de Certeau, La invención de lo cotidiano. 1. Artes de hacer (México: Universidad Iberoamericana, 1996), 110.

37 Eduardo Belgrano Rawson, Fuegia, 66.

38 Eduardo Belgrano Rawson, Fuegia, 16. 
evocado en Fuegia solo tiene sentido desde un presente, un presente que también se vuelve sobre nosotros mismos en el acto de lectura y nos lleva a re-preguntarnos: ¿cómo ha sido esto posible? ¿cómo hemos tolerado esto? Estas historias remotas que componían un paisaje nebuloso común, como el de la propia Tierra del Fuego, adquieren -en virtud de la fuerza y la inmediatez de la reminiscencia- una brutal nitidez y se articulan en una misma memoria dañada con sucesos recientes, interrumpiendo, así, la tranquilidad que proporcionaba la creencia en el progreso histórico. El sentido histórico del texto literario, al menos una parte del mismo, reside precisamente en ese umbral particular que abre la novela, un umbral que da paso a un mundo posible ficcional en el marco de una práctica discursiva estrechamente vinculada con la experiencia de conquista y colonización del territorio que ha dejado huellas concretas en la literatura nacional.

\section{Bibliografía}

\section{Fuentes primarias}

\section{Libros}

Aira, César. Un episodio en la vida del pintor viajero. Rosario: Beatriz Viterbo Editora, 2000.

Alberdi, Juan Bautista. "Fragmento preliminar al estudio del derecho", 1837. En Escritos de Juan Bautista Alberdi: el redactor de la Ley, presentación y selección de textos Oscar Terán. Bernal: Universidad Nacional de Quilmes, 1996, 59-90.

Belgrano Rawson, Eduardo. Fuegia, 1991. Buenos Aires: Seix Barral, 2005. Bridges, Lucas E. El último confín de la Tierra, 1948. Buenos Aires: Emecé, 1952.

Darwin, Charles. Journal of Researches into the Natural History and Geology of the Countries Visited during the Voyage of H.M.S. "Beagle" round the World, under the Command of Capt. Fitz Roy, R.N. Con base en la edición aumentada y corregida de 1845. London-New York-Melbourne: Ward, Lock and Co., 1890. http://nzetc.victoria.ac.nz/tm/scholarly/DarJour-fig-DarJoTit.html. (7 de enero de

196 2014).

Demitrópulos, Libertad. Un piano en bahía desolación, 1994. Madrid: EDAF, 2001. 
Iparraguirre, Sylvia. La tierra del fuego. Buenos Aires: Alfaguara, 1998. Saer, Juan José. Las nubes. Buenos Aires: Seix Barral, 1997.

\section{Fuentes secundarias}

Andermann, Jens. "Crónica de un genocidio: últimas instantáneas de la frontera". En Historia crítica de la literatura argentina. II. La lucha de los lenguajes, editado por Julio Schvartzman. Buenos Aires: Emecé, 2003, 355-381.

Barthes, Roland. “El efecto de realidad”. En El susurro del lenguaje. Más allá de la palabra y la escritura. Barcelona: Paidós, 1994, 179-187.

Belgrano Rawson, Eduardo. "Sacarse de encima la historia". En La historia y la política en la ficción argentina, editado por Sergio Delgado. Santa Fe: Centro de Publicaciones de la Universidad Nacional del Litoral, 1995, 67-72.

Cicerchia, Ricardo. Journey, Rediscovery and Narrative: British Travel Accounts of Argentina. London: Institute of Latin American Studies, 1998.

Cortés Rocca, Paola. "Cuerpos y promesas. El retrato fotográfico en el siglo XIX”. Filología Vol. XXXI. No. 1-2 (1998): 43-56.

De Certeau, Michel. La invención de lo cotidiano. 1. Artes de hacer. México: Universidad Iberoamericana, 1996.

Foucault, Michel. Microfísica del poder. Madrid: Las Ediciones de la Piqueta, 1992.

Foucault, Michel. Hermenéutica del sujeto. Buenos Aires: Fondo de Cultura Económica, 2001.

Garramuño, Florencia. Genealogías culturales. Argentina, Brasil y Uruguay en la novela contemporánea (1981-1991). Rosario: Beatriz Viterbo Editora, 1997.

Geertz, Clifford. Conocimiento local. Ensayos sobre la interpretación de las culturas. Barcelona: Paidós, 1994.

Greimas, Algirdas J. "The Veridiction Contract”. New Literary History Vol. 20.3 (1989): 651-660.

Maddox, Donald. "Veridiction, Verifiction, Verifactions: Reflections on Methodology". New Literary History Vol. 20.3 (1989): 661-677.

Maristany, José. "Un arte de la memoria: Fuegia de Eduardo Belgrano Rawson”. Argos Vol. 42-43 (2005): 76-89. 
Mellado, Luciana. La Patagonia y su literatura: unidad y diversidad multiforme. Comodoro Rivadavia: Universidad Nacional de la Patagonia San Juan Bosco, 2010.

Pratt, Mary Louise. Ojos imperiales. Literatura de viajes y transculturación. Buenos Aires: Fondo de Cultura Económica, 2011.

Prieto, Adolfo. Los viajeros ingleses y la emergencia de la literatura argentina (1820-1850). Buenos Aires: Fondo de Cultura Económica, 2003.

Ricœur, Paul. Temps et récit. II. La configuration du temps dans le récit de fiction. Paris: Seuil, 1984.

Para citar este artículo: Grenoville, Carolina. "Colonizar el espacio,

198 habitar un lugar. Paisaje y ficciones de identidad en Fuegia (1991) de E. Belgrano Rawson", Historia Caribe Vol. X No. 27 (Julio-Diciembre 2015): 177-198. DOI: http://dx.doi.org/10.15648/hc.27.2015.6 